\title{
Increased microvascular fluid permeability in young Type 1 (insulin-dependent) diabetic patients
}

\author{
A.J.Jaap ${ }^{1}$, A.C.Shore ${ }^{1}$, I. B. Gartside ${ }^{2}$,J. Gamble ${ }^{2}$, J.E.Tooke ${ }^{1}$ \\ ${ }^{1}$ Diabetes Research Laboratories, Postgraduate Medical School, University of Exeter, Exeter, UK \\ ${ }^{2}$ Department of Physiology, Charing Cross and Westminster Medical School, London, UK
}

\begin{abstract}
Summary. Microvascular fluid permeability was assessed by determination of the capillary filtration coefficient in the forearm of ten young Type 1 (insulin-dependent) diabetic patients with a short duration of diabetes, satisfactory glycaemic control and minimal evidence of microangiopathy, and ten age- and sex-matched control-subjects. A strain gauge plethysmographic method with a computer based logging and analysis system was used. This enabled differentiation between the volume filling and fluid filtration components of the response to venous pressure elevation. The median capillary filtration coefficient was found to be significantly higher in the young diabetic patients in comparison with control subjects $\left(9.2 \times 10^{-3} \mathrm{ml} \cdot \mathrm{min}^{-1} \cdot 100 \mathrm{~g}\right.$ tissue ${ }^{-1}$.
\end{abstract}

$\mathrm{mm} \mathrm{Hg}{ }^{-1}$ vs $3.8 \times 10^{-3} \mathrm{ml} \cdot \mathrm{min}^{-1} \cdot 100 \mathrm{~g}$ tissue ${ }^{-1} \cdot \mathrm{mm} \mathrm{Hg}^{-1}$, $p<0.001)$. There were no significant correlations between capillary filtration coefficient and either plasma glucose concentration, haemoglobin $\mathrm{A}_{1 \mathrm{c}}$ or duration of diabetes. As there is no evidence from other studies to support an increase in capillary surface area in the forearms of young Type 1 diabetic patients, these results may reflect a primary change in microvascular fluid permeability.

Key words: Capillary filtration coefficient, microcirculation, vascular permeability, strain gauge plethysmography, Type 1 (insulin-dependent) diabetes mellitus.
The haemodynamic hypothesis for the pathogenesis of diabetic microangiopathy [1-3] states that early functional microvascular changes, such as over-perfusion and increased capillary pressure, lead to later irreversible structural changes, characterised by basement membrane thickening and microvascular sclerosis. There is increasing evidence in support of this hypothesis, with evidence of early microvascular over-perfusion [4-6] and increasedcapillary pressure $[6,7]$ in the skin of young diabetic patients. Changes in microvascular permeability may also be important in the genesis of microangiopathy [8]; increased permeability to fluid and a variety of solutes has been demonstrated in Type 1 (insulin-dependent) diabetic patients with moderate to long disease duration $[9,10]$. If increased permeability was present early in the course of diabetes, it would seem more likely to be a primary event, rather than a reflection of earlier adverse microcirculatory changes. One study has shown an increase in microvascular fluid permeability in Type 1 diabetic patients with short disease duration [11], but only during periods of poor metabolic control, which could have affected the results by altering tissue perfusion or the vascular surface area available for exchange. In contrast, other studies have shown normal fluid filtration at this early stage of diabetes [9].
All of these studies have assessed microvascular fluid permeability by calculation of the capillary filtration coefficient (CFC) using the technique of strain gauge venous occlusion plethysmography. CFC, which is also known as hydraulic conductance, is strictly a misnomer as filtration occurs at other sites in addition to the capillaries, notably the post-capillary venules. In these previous studies, CFC calculations were based on the fluid flux response to a single large increase in venous pressure $(>40 \mathrm{~mm} \mathrm{Hg})$. Large pressure steps are known to invoke the veno-arteriolar reflex, a protective local axon reflex activated by a rise in venous pressure [12]. This reflex leads to arteriolar vasoconstriction, thereby attenuating the transmission of arterial pressure to the capillary bed, such as occurs on standing. Abnormalities of this reflex are present from the first year after diagnosis in Type 1 diabetes [13]. It has recently been demonstrated that small increases in venous pressure $(<12 \mathrm{~mm} \mathrm{Hg})$ alter the time course of the vascular filling component of the strain gauge response [14], one possible explanation of which may be that such small pressure steps avoid invoking the veno-arteriolar reflex.

This study therefore used a strain gauge plethysmographic method with a computer based logging and analysis system [15] and employing serial small increases in 
Table 1. Summary of clinical data on Type 1 diabetic patients and control subjects

\begin{tabular}{|c|c|c|c|c|c|c|c|c|c|c|}
\hline & \multirow[t]{2}{*}{$n$} & \multirow{2}{*}{$\begin{array}{l}\text { Sex } \\
(M: F)\end{array}$} & \multirow{2}{*}{$\begin{array}{l}\text { Age } \\
\text { (years) }\end{array}$} & \multirow{2}{*}{$\begin{array}{l}\text { Diabetes } \\
\text { duration } \\
\text { (years) }\end{array}$} & \multirow{2}{*}{$\begin{array}{l}\text { Plasma } \\
\text { glucose } \\
(\mathrm{mmol} / \mathrm{l})\end{array}$} & \multirow{2}{*}{$\begin{array}{l}\mathrm{HbA_{1c }} \\
(\%)\end{array}$} & \multicolumn{2}{|c|}{ Blood pressure } & \multirow{2}{*}{$\begin{array}{l}\mathrm{BMI} \\
\left(\mathrm{kg} / \mathrm{m}^{2}\right)\end{array}$} & \multirow{2}{*}{$\begin{array}{l}\text { Serum } \\
\text { albumin } \\
(\mathrm{g} / \mathrm{l})\end{array}$} \\
\hline & & & & & & & $\begin{array}{l}\text { diastolic } \\
(\mathrm{mm} H \mathrm{Hg})\end{array}$ & $\begin{array}{l}\text { systolic } \\
(\mathrm{mm} \mathrm{Hg})\end{array}$ & & \\
\hline $\begin{array}{l}\text { Control } \\
\text { subjects }\end{array}$ & 10 & $5: 5$ & $\begin{array}{l}26.5 \\
(18-34)\end{array}$ & - & $\begin{array}{l}5.0 \\
(4.0-5.4)\end{array}$ & - & $\begin{array}{l}69.5 \\
(62-80)\end{array}$ & $\begin{array}{l}123 \\
(104-146)\end{array}$ & $\begin{array}{l}20.8 \\
(19.7-27.8)\end{array}$ & $\begin{array}{l}38 \\
(35-44)\end{array}$ \\
\hline
\end{tabular}

Data are shown as median and range.

${ }^{\mathrm{a}} p<0.001$ vs control subjects

cuff pressure, to compare CFC in a group of control subjects and a group of young Type 1 patients with short duration of diabetes, minimal clinical evidence of microangiopathy and satisfactory glycaemic control.

\section{Subjects and methods}

\section{Subjects}

Ten Type 1 diabetic patients (median age 22.0 years, median disease duration 2.8 years) and ten age-and sex-matched control subjects were studied (Table 1). The diabetic group had minimal clinical evidence of microangiopathy (one had mild background retinopathy on ophthalmoscopic examination; all had normal vibration sensory thresholds on biothesiometry and elicitable ankle jerks; none had microalbuminuria as determined by an albumin:creatinine ratio less than 2.5 (urinary albumin $\mathrm{mg} / \mathrm{l}$ divided by urinary creatinine $\mathrm{mmol} / \mathrm{l}$ ) in an early morning urine sample). All the subjects had a random blood glucose concentration between 5 and $15 \mathrm{mmol} / \mathrm{l}$ at the time of the study.

\section{Methods}

Subjects were allowed to acclimatise for $30 \mathrm{~min}$ in a controlled temperature environment $\left(22 \pm 0.5^{\circ} \mathrm{C}\right)$ and during this period average brachial blood pressure was determined from the mean of three readings using an automated blood pressure recorder (Dynamap 845; Critikon Inc, Tampa, Fla., USA). CFC measurements were made on the forearm with the subjects semi-recumbent and the arm supported at heart level. A six-inlet sphygmomanometer cuff (A.C. Cosser, London, UK), which enabled rapid inflation, was applied around the upper arm and inflated using an air pump (Compton type 2D/351 DM; Dawson McDonald and Dawson Ltd, Ashbourne, Dorset, UK), equipped with a multiple resistance air bleed, which permitted stepped increases in occlusion pressure to be applied [16]. The occlusion pressure was monitored using a pressure transducer (type 256-720; RS Components, Corby, UK) coupled to a modified pressure indicator (type 256-758; RS Components). The pressure was monitored close to the cuff. An additional flexible but non-elastic outer cuff was used to minimise cuff compliance and thereby obtain rapid occlusion pressure transmission inwards to the soft tissues of the arm. The mercury-in-silastic strain gauge and gauge holder [14] was applied to the upper one-third of the forearm and the response to serial small increments in cuff pressure (5$12 \mathrm{mmHg}$ every $5 \mathrm{~min}$ ), up to a maximum less than the diastolic blood pressure, was recorded on a microcomputer for subsequent analysis [15]. Once the ambient venous pressure had been exceeded, each increase in cuff pressure generated a characteristic response (Fig.1): an initial rapid exponential phase, due to filling of the compliant venous vessels beneath the gauge, and a concurrent linear phase, due to fluid flux from the microcirculation once pressure was high enough to cause filtration. Values for fluid flux were obtained by least squares fitting of the volume response after the vascular compliance component was completed [14]. The slope of the linear relationship between the values of fluid flux and corresponding cuff pressure represented the CFC (Fig.2). CFC determined by this method was found to be highly reproducible with an intra-individual coefficient of variation of $7.7 \%\left(4.4 \pm 0.34 \times 10^{-3} \mathrm{ml} \cdot \mathrm{min}^{-1}\right.$. $100 \mathrm{~g}_{\text {tissue }}^{-1} \cdot \mathrm{mm} \mathrm{Hg}^{-1}$, mean $\pm \mathrm{SD}$ ) for four measurements on the same subject on separate occasions over a 3 -month period.

At the end of each study, a venous blood sample was taken for estimation of plasma glucose concentration and $\mathrm{HbA}_{1 \mathrm{c}}$ (determined by affinity column chromatography). The study was approved by the local ethical committee and informed verbal consent was obtained from all participants.

\section{Statistical analysis}

As it could not be assumed that data were normally distributed, summary statistics are expressed as median and range and the MannWhitney U Test for two independent samples was used to compare diabetic and control subjects. Associations between different variables were determined using a two-tailed Spearman Rank Correlation Test. All statistical analyses were carried out on a microcomputer using the SPSS/PC + statistical package (SPSS Inc, Chicago, Ill., USA).

\section{Results}

Median CFC (Fig. 3) was significantly greater in the young diabetic patients $\left(9.2 \times 10^{-3} \mathrm{ml} \cdot \mathrm{min}^{-1} \cdot 100 \mathrm{~g}\right.$ tissue ${ }^{-1}$. $\mathrm{mm} \mathrm{Hg}{ }^{-1}$ ) compared with the age- and sex-matched

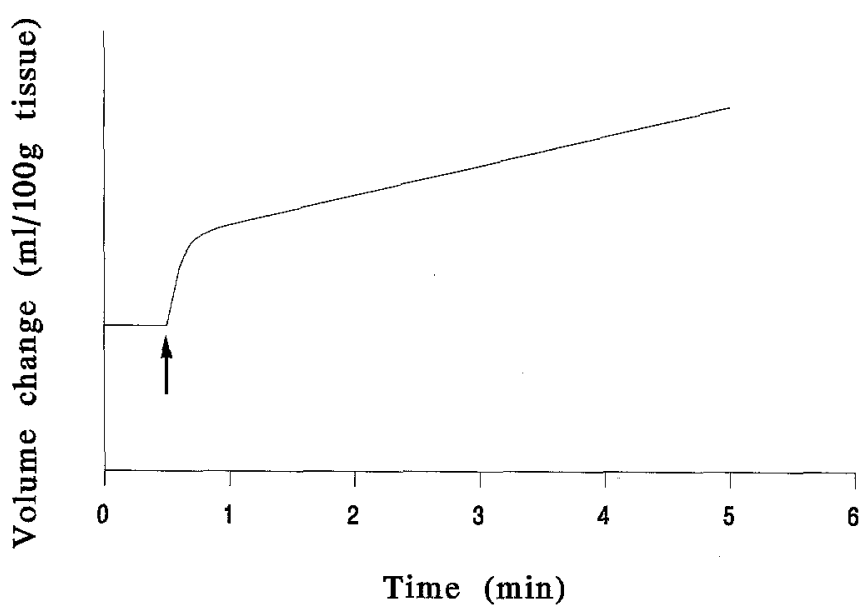

Fig.1. Diagramatic representation of typical recording from the strain gauge in response to an increase in cuff pressure of around $10 \mathrm{mmHg}$ (after ambient venous pressure has been exceeded). Arrow indicates onset of increased cuff pressure. Fluid flux is calculated from the slope of the response between the fourth and fifth minute 


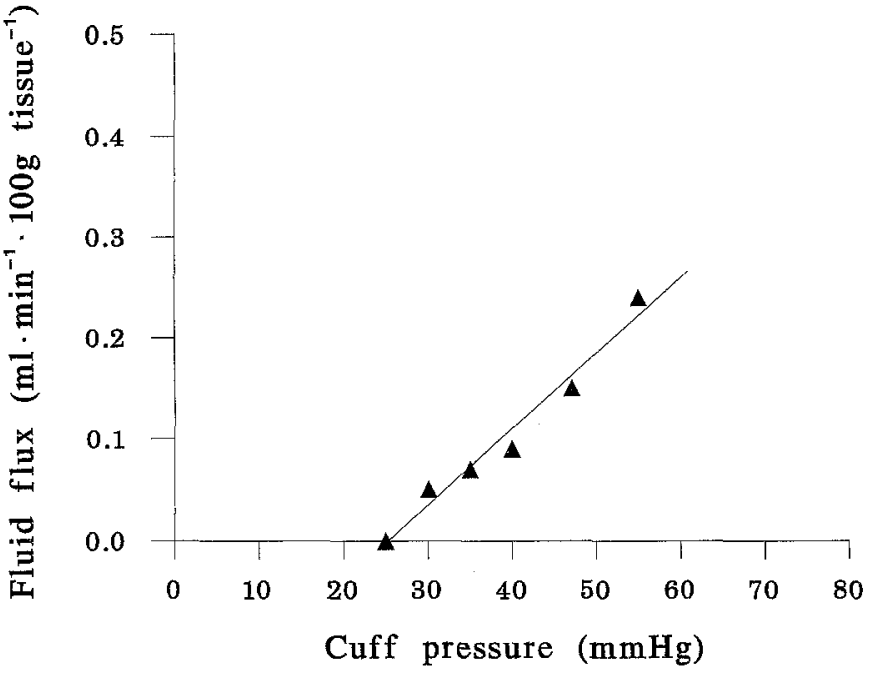

Fig. 2. The linear relationship between fluid flux and cuff pressure for each pressure step. The gradient of the line represents the capillary filtration coefficient (CFC)

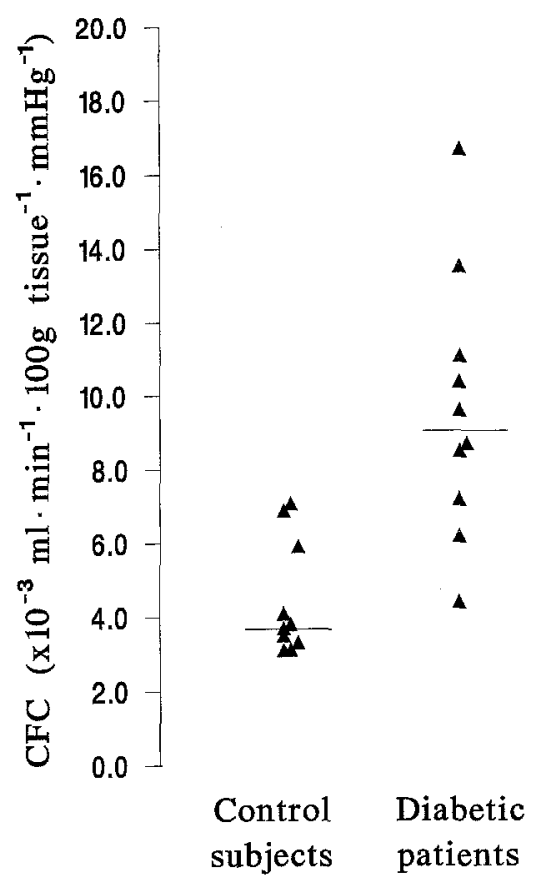

Fig.3. Comparison of capillary filtration coefficient (CFC) values for Type 1 diabetic patients and control subjects (horizontal bars represent median values; $p<0.001$ for difference between patients and control subjects)

control subjects $\left(3.8 \times 10^{-3} \mathrm{ml} \cdot \mathrm{min}^{-1} \cdot 100 \mathrm{~g}\right.$ tissue ${ }^{-1}$. $\left.\mathrm{mm} \mathrm{Hg}{ }^{-1}, p<0.001\right)$. The range of CFC values was greater in the Type 1 diabetic patients $\left(4.4-16.7 \times 10^{-3}\right.$ $\mathrm{ml} \cdot \mathrm{min}^{-1} \cdot 100 \mathrm{~g}$ tissue ${ }^{-1} \cdot \mathrm{mm} \mathrm{Hg}^{-1}$ ) than the control subjects $\left(3.1-7.1 \times 10^{-3} \mathrm{ml} \cdot \mathrm{min}^{-1} \cdot 100 \mathrm{~g}\right.$ tissue $\left.{ }^{-1} \cdot \mathrm{mm} \mathrm{Hg}^{-1}\right)$ and there was some overlap of CFC values between the two groups. There were no differences in forearm circumference (260 mm (235-290) vs $250 \mathrm{~mm}$ (235-290), $p=0.88$ ) or BMI (Table 1) between the diabetic and control subjects. Median plasma glucose at the time of the study was $9.0 \mathrm{mmol} / \mathrm{l}$ (range 5.1-14.4) in the diabetic group (control subjects $5.0 \mathrm{mmol} / \mathrm{l}(4.0-5.4), p<0.001$, normal range $4.2-6.6 \mathrm{mmol} / \mathrm{l})$ and median $\mathrm{HbA}_{1 \mathrm{c}}$ was $7.4 \%(5.5-8.6)$ (normal range 4-6\%). There were no significant correlations between CFC and either plasma glucose concentration, $\mathrm{HbA}_{1 \mathrm{c}}$ or duration of diabetes. No difference was observed in blood pressure or serum albumin concentration (normal range $30-48 \mathrm{~g} / \mathrm{l}$ ) between the patient and control groups (Table 1).

\section{Discussion}

This study demonstrates an increase in capillary filtration coefficient in a group of young, Type 1 diabetic patients with short disease duration and satisfactory glycaemic control who have minimal evidence of microvascular complications. Previous studies using strain gauge plethysmography have failed to demonstrate such a change in similar groups of Type 1 patients $[9,11]$. This may be because the modified plethysmographic method employed in this study gives results which, in our view, are more accurate and reproducible than in previous studies. The CFC calculation in this study is based on the changes in fluid flux in response to several small pressure steps, whereas in previous studies only one large pressure step was used, a technique which may introduce error. The large pressure step, by invoking the veno-arteriolar reflex, may prolong the duration of the vascular filling component thereby increasing the risk of inclusion of this component in the fluid filtration slope [14]. Furthermore, estimation of CFC from a single pressure step can only be performed if the pre-existing venous pressure was at a level that gave rise to filtration [14]. In the present study the elevation in CFC could not be attributed to an effect of hyperglycaemia as there was no correlation with ambient plasma glucose concentration (at least within the range $5-15 \mathrm{mmol} / \mathrm{l}$ ) or $\mathrm{HbA}_{1 \mathrm{c}}$. In addition, there were no significant differences between the diabetic patients and control subjects in arterial blood pressure or serum albumin concentration. The lack of difference in serum albumin concentration makes it unlikely that there was a reduced plasma oncotic pressure leading to an apparent elevation of CFC in the Type 1 patients.

The main determinants of fluid movement across the capillary wall are capillary pressure, the capillary surface area available for exchange and permeability per unit surface area [17]. There is no histological evidence of increased capillary surface area in skeletal muscle in Type 1 diabetes [18], which is the major tissue contributing to fluid flux in the upper forearm. Differences in the tissue composition of the forearm between the Type 1 patients and control subjects are unlikely in view of the similar values for BMI and forearm circumference in the two groups. Moreover, venous occlusion should elevate microvascular pressure within the whole microvascular network, thereby eliminating any possible contribution from differences in homogeneity of tissue perfusion in the patient and control groups.

Techniques for direct measurement of capillary pressure in the skeletal muscle, adipose or connective tissue 
in the upper forearm of man are not yet possible; however measurement of finger nailfold capillary pressure may provide some indication of whether abnormalities of microcirculatory pressure are present. Finger nailfold capillary pressure has been shown to be elevated in Type 1 diabetic patients with short disease duration and correlates with glycaemic control [7]. A number of mechanisms have been postulated by which such an elevation in capillary pressure may influence microvascular structure and permeability [1-3, 19], although currently there is debate over whether capillary hypertension leads to an increase [20] or decrease [21, 22] in microvascular fluid permeability. This can only be resolved when simultaneous measurements of microvascular pressure and permeability become possible in vivo.

It is possible that the increased CFC may not reflect capillary hypertension or changes in surface area but a primary change in the fluid permeability of the microcirculation in Type 1 diabetes. The main pathway for fluid filtration across the microvascular wall is through channels between endothelial cells which are filled with a lattice of glycocalyx material [23], and subsequently through a further glycoprotein lattice in the basement membrane. Separation or loss of endothelial cells [24], or glycation of proteins in the glycocalyx and basement membrane [25], leading to altered structure or charge [8] are possible mechanisms that could alter effective pore size and therefore fluid permeability. It is interesting to draw parallels between increased CFC in the forearm and the glomerular hyperfiltration [26] which is present in Type 1 patients with a short duration of diabetes. It must be remembered, however, that the glomerulus is a hemi-arteriole in contrast to the capillaries and venules of the microcirculation in the forearm tissues. Moreover, glomerular hyperfiltration has been shown to partly relate to an increase in renal plasma flow [26] and filtration surface area [27], although there is also some indirect evidence supporting a role for raised intraglomerular hydrostatic pressure $[28,29]$.

It is noteworthy that not all the diabetic patients had a CFC value above the normal range and it may be that only those with early abnormal microvascular function, such as increased CFC, go on to develop severe microvascular complications. This requires future confirmation in prospective studies.

In summary, this study demonstrates for the first time an increase in microvascular permeability to water in a group of young Type 1 diabetic patients with a short duration of diabetes and satisfactory glycaemic control, who have minimal evidence of microangiopathy.

Acknowledgements. The authors would like to thank Ms. P.Figgis and Mr. A. Webb for their help in gathering data. This work was supported by ICI Pharmaceuticals, the Wellcome Trust and Zyma Pharmaceuticals.

\section{References}

1. Tooke JE (1986) Microvascular haemodynamics in diabetes mellitus. Clin Sci 70: 119-125

2. Parving H-H, Viberti GC, Keen H, Christiansen JS, Lassen NA (1983) Haemodynamic factors in the genesis of diabetic microangiopathy. Metabolism 32: 943-949

3. Zatz R, Brenner BM (1986) Pathogenesis of diabetic microangiopathy: the haemodynamic view. Am J Med 80: 443-453

4. Kohner EM, Hamilton AM, Saunders SJ, Sutcliffe BA, Bulpitt CJ (1975) The retinal blood flow in diabetes. Diabetologia 11: 27-33

5. Christiansen JS, Gammelgaard J, Tronier B, Svendsen PA, Parving $\mathrm{H}-\mathrm{H}$ (1982) Kidney function and size in diabetics, before and during initial insulin treatment. Kidney Int 21: 683-688

6. Rayman G, Williams S, Hassan A, Gamble J, Tooke JE (1985) Capillary hypertension and overperfusion in the feet of young diabetics. Diabetic Med 2 [Suppl]: 304 A (Abstract)

7. Sandeman DD, Shore AC, Tooke JE (1992) Relation of skin capillary pressure in patients with insulin-dependent diabetes to complications and metabolic control. N Engl J Med 327: 760764

8. Deckert T, Feldt-Rasmussen B, Borch-Johnsen K, Jensen T, Kofoed-Enevoldsen A (1989) Albuminuria reflects widespread vascular damage: the Steno hypothesis. Diabetologia 32: 219 226

9. Poulsen HL, Nielsen SL (1976) Water filtration of the forearm in short- and long-term diabetes mellitus. Diabetologia 12: 437-440

10. Alpert JS, Coffman JD, Balodimos MC, Koncz L, Soeldner JS (1972) Capillary permeability and blood flow in skeletal muscle of patients with diabetes mellitus and genetic prediabetes. $\mathrm{N}$ Engl J Med 286: 454-460

11. Parving H-H, Noer I, Deckert T et al. (1976) The effect of metabolic regulation on microvascular permeability to small and large molecules in short-term juvenile diabetics. Diabetologia 12:161166

12. Henriksen O (1977) Local nervous mechanism in regulation of blood flow in human subcutaneous tissue. Acta Physiol Scand 97: 385-391

13. Tooke JE, Lins P-E, Östergren J, Fagrell B (1985) Skin microvascular autoregulatory responses in Type 1 diabetes: the influence of duration and control. Int J Microcirc Clin Exp 4: 249-256

14. Gamble J, Gartside IB, Christ F (1993) A reassessment of mercury in silastic strain gauge plethysmography for microvascular. permeability assessment in man. J Physiol 464: 407-422

15. Gamble J, Gartside IB (1989) A four-channel recording system using an IBM PC/XT compatible computer for low frequency data sampling during mercury-in-rubber strain gauge plethysmography in humans. J Physiol 413: 7 p (Abstract)

16. Gartside IB, Gamble J (1991) Apparatus for the production of step changes in cuff pressure for venous occlusion plethysmography in man. J Physiol 438:10p (Abstract)

17. Michel CC (1979) The investigation of capillary permeability in single vessels. Acta Physiol Scand 463 [Suppl]: 67-74

18. Leinonen H, Matikainen E, Juntunen J (1982) Permeability and morphology of skeletal muscle capillaries in Type 1 (insulin-dependent) diabetes mellitus. Diabetologia 22: 158-162

19. Williamson JR, Kilo C (1977) Current status of capillary basement-membrane disease in diabetes mellitus. Diabetes 26: 6573

20. Dull RO, Jo H, Sill H, Hollis TM, Tarbell JM (1990) The effect of varying albumin concentration and hydrostatic pressure on hydraulic conductivity and albumin permeability of cultured endothelial monolayers. Microvase Res 41:390-407

21. Fisher RF (1982) The water permeability of basement membrane under increasing pressure: evidence for a new theory of permeability. Proc R Soc Lond [Biol] B216: 475-496

22. Robinson GB, Walton HA (1989) Glomerular basement membrane as a compressible ultrafilter. Microvase Res 38: 36-48

23. Curry FE, Michel CC (1980) A fiber matrix model of capillary permeability. Microvasc Res 20: 96-99 
24. Katz MA, McCuskey P, Beggs JL, Johnson PC, Gaines JA (1989) Relationships between microvascular function and capillary structure in diabetic and non-diabetic human skin. Diabetes 38: $1245-1250$

25. Brownlee M, Vlassara H, Cerami A (1984) Non-enzymatic glycosylation and the pathogenesis of diabetic complications. Ann Int Med 101: 527-537

26. Christiansen JS, Gammelgaard J, Frandsen M, Parving H-H (1981) Increased kidney size, glomerular filtration rate, and renal plasma flow in short-term insulin-dependent diabetics. Diabetologia 20: 451-456

27. Østerby R, Parving H-H, Nyberg G et al. (1988) A strong correlation between glomerular filtration rate and filtration surface in diabetic nephropathy. Diabetologia 31: 265-270

28. Mogensen CE (1976) Renal functional changes in diabetics. Diabetes 25: $872-879$
29. Zatz R, Dunn R, Meyer TW, Anderson S, Rennke HG, Brenner BM (1986) Prevention of diabetic glomerulopathy by pharmacological amelioration of capillary hypertension. J Clin Invest 77: $1925-1930$

Received: 11 January 1993

and in revised form: 5 March 1993

Dr. A. Jaap

Diabetes Research Laboratories

Noy Scott House

Haldon View Terrace

Exeter EX2 5EQ

UK 